\title{
Using bridge weigh-in-motion systems to monitor single-span bridge influence lines
}

\author{
Aleš Žnidarič ${ }^{1}\left[\mathbb{0} \cdot\right.$ Jan Kalin ${ }^{1}$
}

Received: 15 December 2019 / Revised: 10 May 2020 / Accepted: 12 May 2020 / Published online: 31 July 2020

(c) The Author(s) 2020

\begin{abstract}
Bridge weigh-in-motion systems use instrumented bridges or culverts to weigh vehicles as they pass over the structures. They also provide data to allow the calculation of several bridge performance indicators. The article starts with the basics of a bridge weigh-in-motion system and briefly describes two key bridge performance indicators, girder distribution factor and dynamic amplification factor, which are also derived from B-WIM measurements. The central part of the article focuses on monitoring of influence lines, the third key parameter that characterises the bridge performance under traffic loads. First, the method of calculating the bending moment influence lines from random heavy traffic is described. A coefficient of rotational stiffness is introduced, which defines the shape of influence lines around the supports as a linear combination of the ideal simply supported and fixed supported influence lines, to allow quantifying the influence line changes. Then the long-term monitoring of influence lines is investigated on four different single-span test bridges. The initial focus is given on the examination of the effect of temperature on the shape of influence lines. Finally, two sets of influence lines are compared on one test bridge, one from before and the other from after replacing the expansion joints and bearings. The work done so far confirms that calculating of influence lines from random vehicles with a B-WIM system is entirely feasible and that differences in their shape can be detected on single-span bridges. What remains to be investigated is the comparison of these differences to the actual damages and under which circumstances the proposed procedure can compete with or better the routine bridge inspection and the conventional monitoring techniques.
\end{abstract}

Keywords Bridge loading $\cdot$ Bridge response $\cdot$ Temperature dependency $\cdot$ Influence line $\cdot$ Monitoring

\section{Introduction}

The condition of bridges is a vital performance indicator needed for efficient management of transport infrastructure. In most cases, it is assessed from the results of bridge inspections and of various structural health monitoring (SHM) procedures. These procedures are assisting the stakeholders with additional information about the evolution of their infrastructure, to improve decisions about the design, operation, and management of bridges throughout their lifespans. SHM procedures have been around for decades and vary considerably depending on the technologies applied. The most common are monitoring of ambient vibration, of deflection and displacements, of fatigue, of corrosion,

Aleš Žnidarič

ales.znidaric@zag.si

1 Slovenian National Building and Civil Engineering Institute, Dimičeva 12, 1000 Ljubljana, Slovenia carbonisation and chloride content, of material properties, of load transfers [1] and actual load effects [2]. The SHM procedures are typically designed for specific purposes and include dedicated instrumentation to obtain the required information. As the operation of long-term installations is costly, they are predominantly used on larger and critical bridges.

The idea behind the presented work is not to set up a standalone bridge monitoring system but to (a) benefit from the existing instrumentation that has been installed to weigh vehicles in motion, and (b) to extend the SHM applications to smaller bridges. The proposed procedure applies bridge weigh-in-motion (B-WIM) measurements to monitor influence lines of bridges and to detect possible changes in their behaviour. B-WIM is a method that uses an instrumented bridge or culvert to weigh heavy vehicles while they cross the structure. These systems provide an equivalent set of vehicle parameters (axle loads, gross weight, axle spacing, velocity, vehicle category) as the more common pavement 
WIM systems, but also have some specific advantages. Two of them are (a) complete portability of instrumentation and (b) no need for any sensors on the pavement, which ensure installations and maintenance activities without interrupting the traffic [3]. Finally, one can use the collected strain records to evaluate the actual bridge performance indicators (influence lines, dynamic amplification of traffic loads and load distribution factors), which allows optimisation of the bridge assessment procedures $[4,5]$. The result is more efficient, sustainable and cost-effective decision-making, both on the network and the project levels.

After a short description of the B-WIM algorithm, the paper briefly describes the girder distribution factors and the dynamic amplification factor, to give a complete picture of the abilities of the B-WIM system in providing data for optimised bridge analysis. The core of the work deals with long-term measurements of influence lines as a tool to detect changes in bridge performance under traffic loading. First, the effects of temperature on the shape of the influence lines were studied on four test bridges. Finally, long-term monitoring of the influence lines was thoroughly investigated on one of those bridges, which boundary conditions changed due to the replacement of bearings and expansion joints.

\section{About bridge weigh-in-motion}

The initial research, which ultimately resulted in the first B-WIM algorithm, originated from the need to know bridge performance under real traffic loading [6]. This work evolved in the still-valid principles of weighing vehicles in motion with bridges [7]. The following decade saw the first unmanned versions of B-WIM systems, first applied in Australia on culverts [8, 9], and soon after in the USA [10].

In the 1990s, B-WIM technology matured considerably in two research projects supported by the European Commission: COST 323 [2] and WAVE [11]. In the calculations, the analytical influence lines replaced the measured ones, installations on bridges other than just of the beam-and-slab type were tested, and some new axle detection technologies were developed. The WAVE project also investigated several alternative B-WIM algorithms, including a two-dimensional one that indicated the potential for flexible orthotropic decks $[12,13]$, and the one that included the dynamic interaction of the vehicle-bridge system in the axle load calculation [14]. Another key result was the free-of-axle detector (FAD) installation, with strain measurements on the bridge soffit replacing the costly and fragile axle detectors on or in the wearing course of pavement. Finally, during the WAVE project the Slovenian National Building and Civil Engineering Institute (ZAG) developed a B-WIM prototype system, which was ultimately commercialised and was over the years equipped with several bridge assessment modules $[15,16]$.
In Japan in the eighties, instrumented vertical stiffeners on the web of steel plates were used as axle detectors, with mixed success. Also investigated were crack openings in the reinforced concrete slabs to detect axles [17], B-WIM in orthotropic steel decks [18] and optical devices to monitor bridge deflections under traffic loading [19]. All to predict the axle loads.

Helmi [20] and Bao [21] with their teams replaced the measurements of bending moments with measurements of shear forces near the supports of the bridges. They utilised fibre-optic rosette sensors for the implementation of this approach. Development of the method involved the use of shear-strain influence lines and led to alternative systems of equations to calculate truck axle weights and spacing.

Several authors pursued the Moving Force Identification (MFI) theory that applies complex bridge-vehicle interaction to calculate the axle loads. Its goal is to find the best fit between the finite element (FE) model and the measured response of the bridge, to calculate the time-dependent dynamic axle loads [22-24]. This approach requires substantial computing power, but the results on generic data gave promising results concerning the accuracy of axle loads, compared to the conventional B-WIM method. Unfortunately, when using strain records measured on bridges shorter than $30 \mathrm{~m}$, the accuracy of the results improved less than predicted in simulations [25]. Longer spans still need to be investigated.

Today, B-WIM research is regaining attention in the USA, often associated with bridge assessment [26-29]. Some significant steps forward in the accuracy and long-term stability of B-WIM results were achieved in the recent research projects TRIMM [30] and BridgeMon [31, 32]. The latter demonstrated improved long-term stability and accuracy of B-WIM results, developed more effective axle detection and strain measurement strategies and studied the influences of temperature, varying vehicle velocity and pavement roughness on the accuracy of results [3]. In the TRIMM project, among others, we studied the use of B-WIM as a tool for long-term monitoring of the influence lines, to detect changes in the behaviour of bearings and expansion joints.

\subsection{Conventional B-WIM algorithm}

Figure 1 shows a typical B-WIM installation of a beamand-slab bridge. The sensors around the mid-spans are used for calculation of the influence lines and for weighing. The separate pairs of sensors under each driving lane detect the crossing axles. They are attached to the slab between the beams or the bottom flange of the beams. The top left corner of Fig. 1 displays an enlarged photo of the strain transducer, with a $200-\mathrm{mm}$ base, that was used in this study at all measuring locations. 


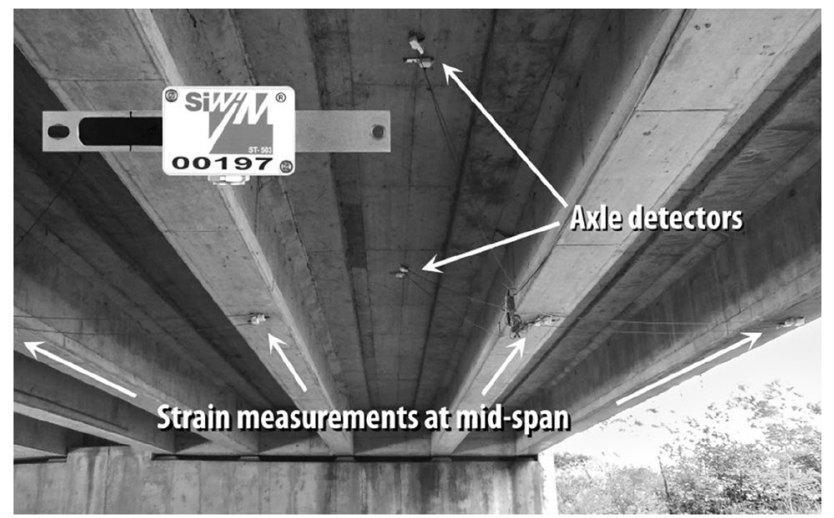

Fig. 1 B-WIM instrumentation of a beam-and-slab bridge

The conventional B-WIM algorithm works on the static assumption, similar to the one proposed by Moses [7]. Strains are measured on the main longitudinal members of a bridge and the gross bending moment, due to a vehicle loading, is found by summing the individual moments

$M=\sum_{i}^{G} M_{i}=E W \sum_{i}^{G} \varepsilon_{i}=\mathrm{CF} \sum_{i}^{G} \varepsilon_{i}$,

where $M_{i}$ and $\varepsilon_{i}$ are the bending moment and the corresponding strain in the $i$ th girder or section of the superstructure. $E$ is the modulus of elasticity, $W$ is the section modulus, $G$ represents the number of considered measured locations and $\mathrm{CF}$ is the calibration factor. $E$ modulus is assumed constant, and $W$ modulus is selected to account for the entire superstructure. Consequently, the product of $E$ and $W$ is substituted with the calibration factor $\mathrm{CF}$ that is obtained as a result of calibration process: the statistically evaluated axle loads and gross weights, provided by the B-WIM system for one or more vehicles, are correlated with the corresponding values measured on a static scale.

The B-WIM analysis is an inverse-type problem where the strains are measured, and the live load causing the strains is calculated. The number of unknowns for each vehicle is equal to the number of axles, $K$. They are determined by at least $K$ bending moments, calculated at different longitudinal positions of the vehicle along the bridge. The equations require the bending moment influence lines, $I(x)$, obtained from the measured bridge responses. In B-WIM theory, an influence line describes the variation of bending moment at the measuring location under a unit load that crosses the bridge.

The goal of B-WIM is to solve the system of $N$ equations:

$$
M\left(t_{j}\right)=\sum_{n=1}^{N} A_{n} I\left(v_{n}\left(t_{n}-t_{j}\right)\right) ; j=1 \ldots K,
$$

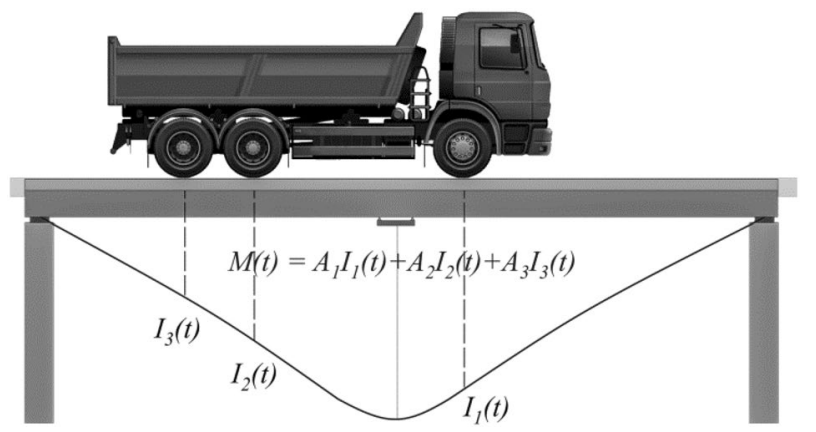

Fig. 2 Using an influence line to calculate the bending moment of a three-axle vehicle

where $M\left(t_{j}\right)$ are the bending moments at $K$ different times, $A_{i}$ are the unknown axle weights, $v_{n}$ are the measured axle velocities, $t_{n}$ are the arrival times of individual axles, and $N$ is the number of axles. The number of measurements, $K$, must be greater or equal to $N$, an easily achievable condition, with typical crossing times on the order of seconds and a standard sampling rate of 512 samples per second. Figure 2 shows the theoretical principle of using a bending influence line to calculate the bending moment of a three-axle vehicle at time $t$, in terms of $K$ unknown axle weights, in this case $A_{1}$ to $A_{3}$.

A more detailed description of the conventional B-WIM algorithm is given, for example, in [3].

\subsection{Bridge performance indicators}

Bridge monitoring aims to provide quality information for a more cost-efficient as well as environment- and userfriendly assessment of bridges. In addition to delivering strain responses of a bridge superstructure under the crossing vehicles, the B-WIM system can calculate in realtime three important bridge performance indicators [5]:

1. The influence lines (IL), which define how the bridge performs under the traffic loads,

2. Girder distribution factor (GDF), which tells how loading spreads over the superstructure, and

3. Dynamic amplification factor (DAF), which quantifies the supplementary load effects due to the bridge-vehicle interaction.

Measuring these indicators reduces the uncertainties of information, which allows for more optimal bridge analysis $[30,33]$. Following is a brief description of GDF and DAF evaluation procedures, to provide a complete picture of the B-WIM system abilities to measure realistic bridge performance. The influence lines, as the central topic of the paper, are described in detail in Sects. 3 and 4. 


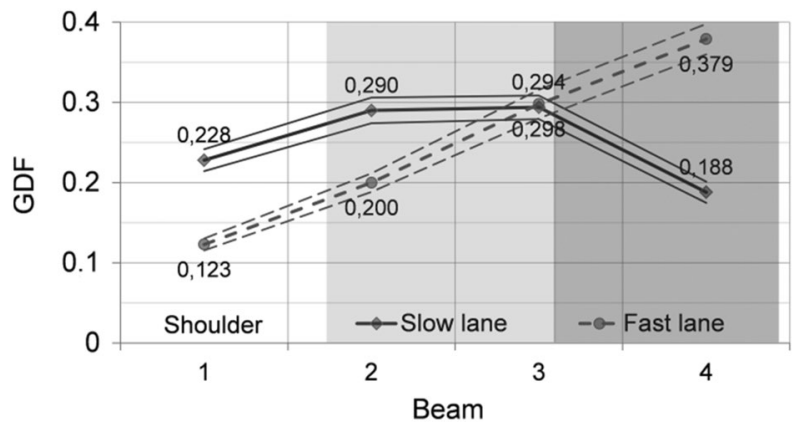

Fig. 3 An example of measured GDF

\subsubsection{Girder distribution factor}

Thousands of measured strain signals caused by a continuous traffic flow are processed to evaluate the distribution of traffic loads over the main structural members of a bridge. The first step is to find the maximum strains for each of the $l=1 . . L$ loading events, caused by individual heavy vehicles, weighing 3.5 tonnes and above, that crossed the bridge. For reliable results, $L$ should be in a range from a few ten to a few hundred. The girder distribution factors for each of these events, $\mathrm{GDF}_{\mathrm{k}}$, are defined as shares of the sum of maximum strains measured on each relevant beam, girder or section of a slab, $G$. Figure 3 shows the results, calculated from 4550 strain records, from a 40-m long motorway bridge with four prestressed concrete beams, cross-beams at supports, at midand quarter-spans, and carrying a shoulder and two lanes of traffic. The graph displays the mean values and the \pm 1 standard deviation intervals of GDF values for each of the two driving lanes. Within the structural analysis, we finetune the boundary conditions and properties of the structural elements of the model in a way that the calculated and the measured GDF values match, to allow the numerical model to describe as accurately as possible the actual performance of the bridge.

\subsubsection{Dynamic amplification factor}

In most cases, the dynamic component of bridge response due to the traffic loading is represented by the dynamic amplification factor (DAF). In the codes, this factor is typically more conservative than in reality, as was shown in the theoretical studies by Kirkegaard et al. [34] and in the measured results of the ARCHES project [4]. This project demonstrated that DAF could be efficiently measured with a B-WIM system. A procedure was developed that automatically calculated the DAF values for all loading events caused by vehicles crossing the bridge, and using a common definition [35]:
$\mathrm{DAF}=\frac{\varepsilon_{\mathrm{T}}}{\varepsilon_{\mathrm{S}}}$,

where the total load effect of vehicles from free-flowing traffic, $\varepsilon_{\mathrm{T}}$, is typically larger than the static one, $\varepsilon_{\mathrm{S}}$. In the case of B-WIM, $\varepsilon_{\mathrm{T}}$ is the maximum measured strain amplitude, and $\varepsilon_{\mathrm{S}}$ is the maximum value of the estimated static response. Today, the static response is calculated by filtering the measured signals [36]. The characteristic frequency of the dynamic component is assumed to be higher than the frequencies present in the static component. Consequently, the signal is transformed into the frequency domain using fast Fourier transform [37]; the spectrum is low-pass filtered and transformed back into the time domain. The remains are taken as the static load effect and are used in the calculation of the DAF value (Fig. 4). The low-pass filter is characterised by a cut-off frequency, obtained by analysing a large number of loading events, as described in detail in [36]. Dividing the maximum values of the measured with the evaluated static responses gives the DAF estimate for the particular loading event.

Finally, DAF values of all loading events are presented as a function of the gross vehicle weight or the measured strains. Results from a typical highway overpass with three spans, with six continuous steel girders and a concrete deck, are given in Fig. 5. This diagram shows 29,000 DAF values as a function of gross weight, and in Fig. 6, in the form of a histogram. Despite the high values at lower gross weights, the DAF values converge to 1 as the total weight of the loading event, and the corresponding load effects and the maximum strains, increase. The actual dynamic amplification for the heaviest loading events is therefore much smaller than taken into account in bridge codes. This reduction of DAF corresponds to the findings from the literature [34-36] and can optimise substantially the remedial measures resulting from bridge safety assessment.

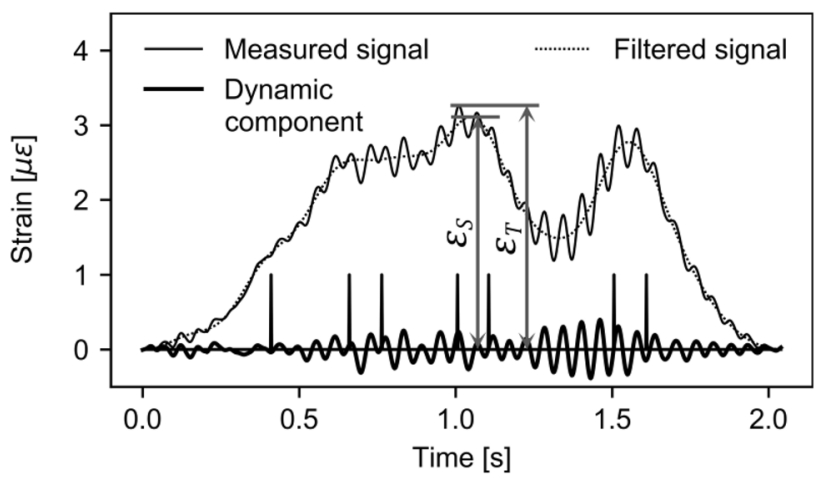

Fig. 4 Measured signal under a seven-axle vehicle, decomposed to its static and dynamic component; spikes give locations of individual axles 


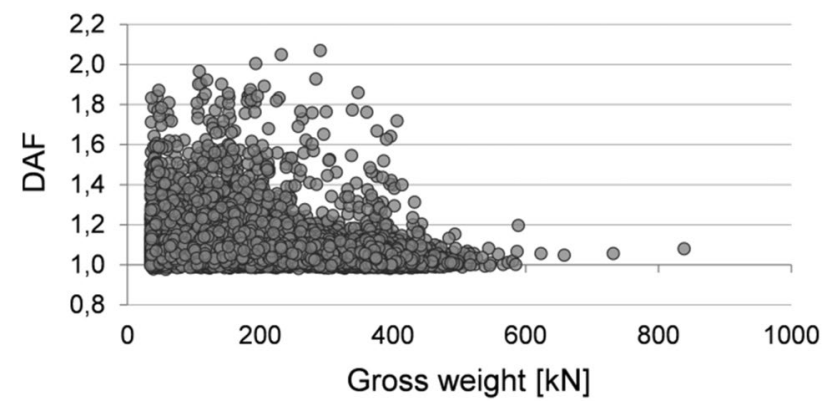

Fig. 5 Measured DAF values as a function of GVW

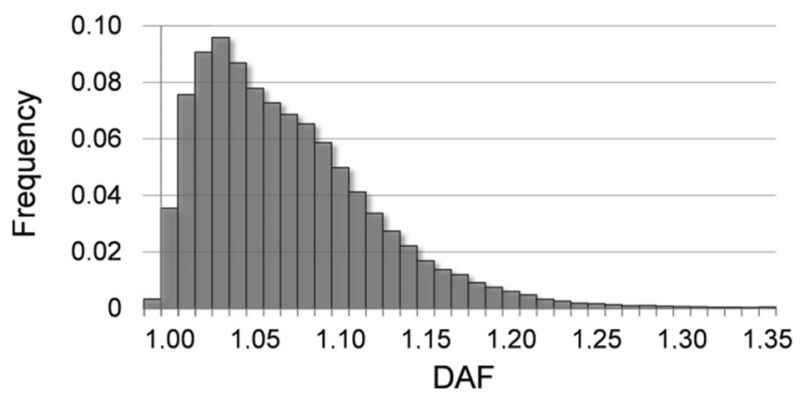

Fig. 6 Histogram of measured DAF values

\section{Influence line calculation method}

This section describes the adopted method to calculate the influence lines from random traffic with a B-WIM system. Then it presents the four typical bridges on which the method was validated, discusses robustness of the calculation procedure and, finally, discusses how temperature can affect the shape of the influence lines.

\subsection{Calculating influence lines from B-WIM measurements}

In engineering, an influence line, also know as unit influence line, is a function that describes the response of the structure at a given point under the moving unit load. In other words, the influence lines describe how the load effects, bending moment or shear force, vary under the moving traffic loads. In practically all cases, the measured influence lines differ from the theoretical ones. The diversities are more pronounced on older bridges where the bearings and expansion joints, due to their condition and construction practice, do not perform according to the theoretical assumptions and expectations. The B-WIM algorithms, to provide accurate axle loads, have to employ the actual influence lines that can only be calculated from measurements [15]. The same influence lines play a vital role in the improved bridge assessment.

There have been some attempts to develop influence lines based on measurements. Hirachan and Chajes [38] tested a method that was based on the response of a movable steel bridge that was crossed by two pre-weighed trucks with the same axle spacing but different load distribution. Wang et al. [39] proposed a fitting method to find the actual IL of the bridge based on its theoretical model and the characteristics of bridge vibration. They have shown that applying this method reduced the influence of vehicle velocity, but had also acknowledged that the accuracy was sensitive to road surface conditions. For practical applications, two methods for calculating the measured IL must be mentioned: the matrix method and the ZAG method. The matrix method uses vehicles of known weight and configuration. It performs a linear optimisation to find the best fit of the influence line ordinate at each location across the bridge [27, 40]. The ZAG method implements a non-linear optimisation, using a high number of random vehicles from the traffic flow, of unknown axle loads, to calculate the shape of the influence line [3]. An advantage of this method is that the IL shape is less dependent on the characteristic dynamic bridge and vehicle responses, which can influence the results when only a few pre-weighed vehicles are used.

The ZAG method uses the same set of Eq. (2) as for weighing. The difference is that here the influence lines are also unknown and are calculated as a part of the process. The influence lines are constructed from cubic splines. Splines are curves of the third order, smooth in derivatives and continuous in the second derivatives [37]. Consequently, they describe well the characteristics of the bridge influence lines. Figure 7 demonstrates the principle of its generation on a hypothetical three-span bridge. Three types of control points define the influence line. The white ones represent the supports; their abscissas are defined by bridge geometry, while their ordinates are fixed to zero. The exception is the point $\mathrm{M}$, located at the point of interest, typically where the

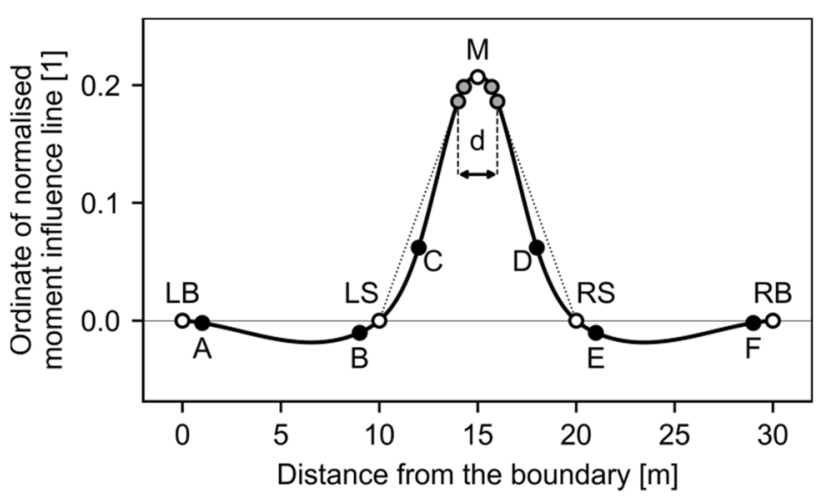

Fig. 7 Generation of influence line with cubic splines 
highest strains or load effects are expected, and the measurements are taking place, for which the ordinate is also optimised.

The grey points define the radius $d / 2$ of the rounded cap, which is modelled to improve the fit between the measured and modelled responses. Finally, the optional black points A through $\mathrm{F}$ can fine-tune the match. Their $x$-coordinates are selected and $y$-coordinates are optimised. The ordinates of the curve between the control points are obtained with cubic spline interpolation [37].

Influence lines are generated from the bridge strain responses caused by the most frequent heavy vehicles, typically five-axle semi-trailers and three- or four-axle rigid trucks. Using hundreds of random vehicles of different types mitigates the anomalies in the shape of the ILs that might be integrated into the IL as a result of bridge-vehicle interaction and dynamic characteristic of some types of vehicles [41]. The resulting influence line is calculated by averaging at least a few tens of individual ones.

In theory, there are no limitations on the number of spans and length of calculated IL. However, if it is longer than about $40 \mathrm{~m}$, regardless if it covers one or spreads over more spans, the probability of having more than one vehicle in each traffic lane increases. These events not only complicate the IL calculation but also gradually reduce the accuracy of B-WIM results [33].
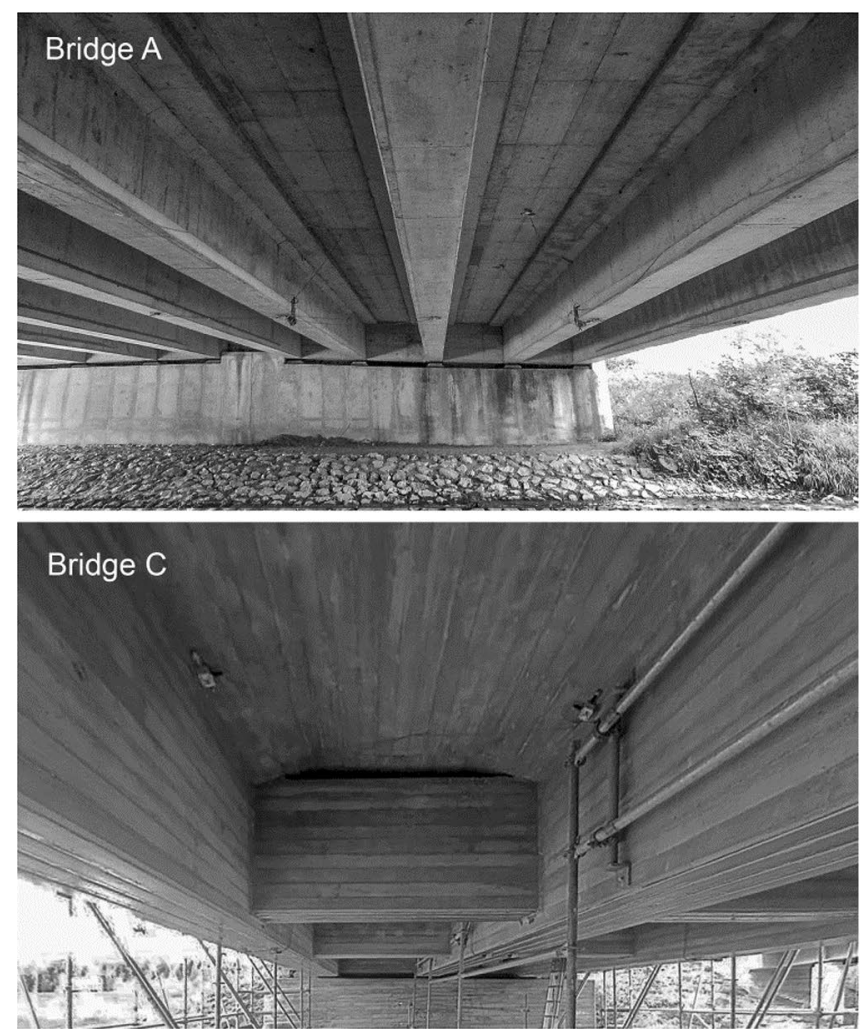

A more comprehensive description of the influence line calculation with the ZAG method is given in [3].

\subsection{Test bridges}

Results from four single-span bridges (Fig. 8) demonstrate the efficiency of the influence line calculation. Two bridges have a beam-and-slab superstructure and two are short integral bridges. The continuous multi-span bridges are equally suitable for B-WIM measurements and influence line calculation. For example, Fig. 9 compares the measured and the modelled responses of a reinforced concrete bridge over 6.5- and 8.0-m-long spans, during the crossing of a twoaxle heavy vehicle. The measured strains are multiplied by the calibration factor $\mathrm{CF}$ (Eq. 1), and the modelled bending moments are calculated using Eq. 2. The figure also displays the individual axle contributions, which follow the IL shape generated with the ZAG method. As we did not possess long-enough datasets from multi-span bridges that would allow comparison of their IL shapes over time, we did not consider multi-span bridges in this study.

\subsubsection{Single-span beam-and-slab bridges}

Bridge $\mathrm{A}$ is a typical medium-span motorway beam-and-slab bridge. It has a single simply supported span of $24.8 \mathrm{~m}$. The

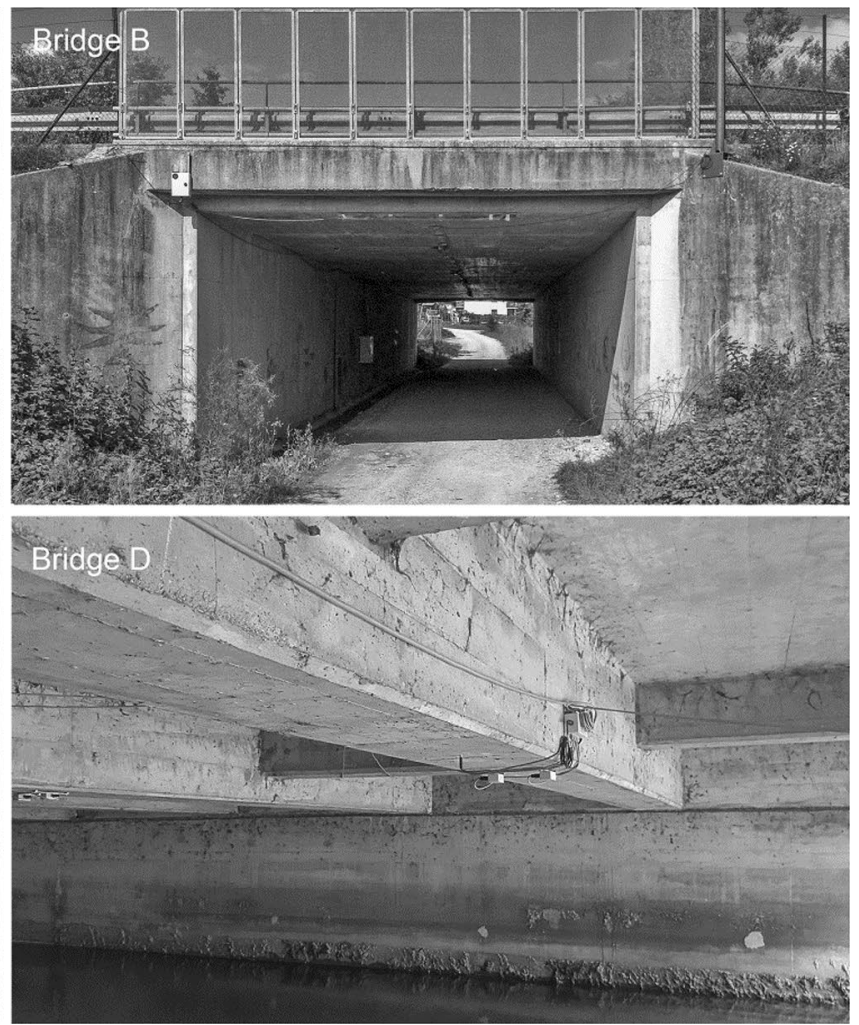

Fig. 8 The four test bridges 


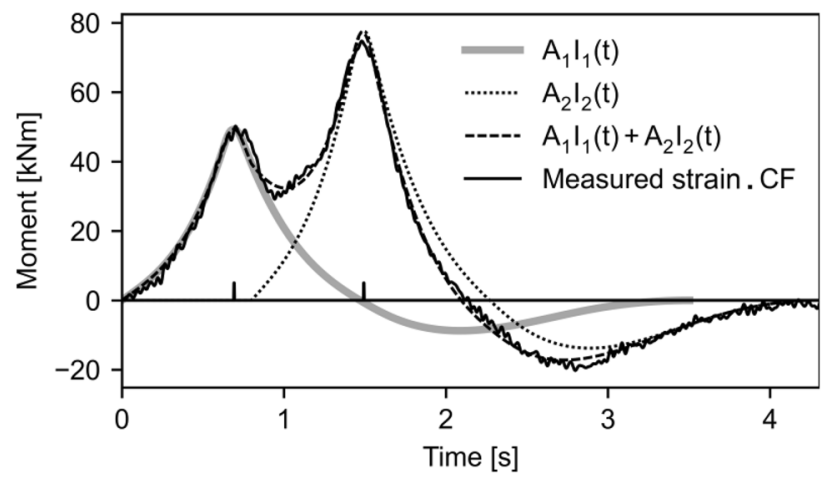

Fig. 9 Measured and modelled two-span bridge responses

independent superstructures, one for each direction of traffic, are made of five 1.4-m-deep prefabricated prestressed beams, with a 0.24 -m-thick reinforced concrete deck on the top. Reinforced elastic neoprene bearings support each longitudinal beam at both ends of the bridge. Cross-beams connect the main beams over both abutments. During the reconstruction of the motorway section, the rubber expansion joints were replaced with the asphalt ones. Due to different technologies, we expected that the new expansion joints would affect the rotations of the supports, and would change the shape of the influence lines. Thus, we chose this bridge to demonstrate the feasibility of detecting changes in bridge behaviour by monitoring influence lines.

The older Bridge $\mathrm{C}$ carries two lanes of traffic and is composed of three 1-m-high reinforced concrete beams with cast-in-place reinforced concrete deck over them. The span between the supports is $13.2 \mathrm{~m}$. It has cross-beams at one-third and two-third of the span length. The bridge was designed as simply supported but did not have bearings and expansion joints.

\subsubsection{Integral bridges}

The integral reinforced concrete bridges, from now on referred to as the Bridges B and D, are 6- and 10.5-m-long motorway underpasses which carry four lanes of traffic. The thickness of the slab of Bridge B is around $0.6 \mathrm{~m}$ and of the grillage of Bridge $\mathrm{D}$ about $1.0 \mathrm{~m}$. They both consist of two independent structures, each carrying two lanes of traffic and a shoulder. Such structures are widely used for the installation of B-WIM systems.

\subsection{Robustness of the measured influence lines}

Robustness of the ZAG method, with respect to convergence of the shapes of the influence lines, is first demonstrated on Bridge A. Figure 10 summarises the results of averaging of 10, 43, 530 and all 2505 influence lines. These

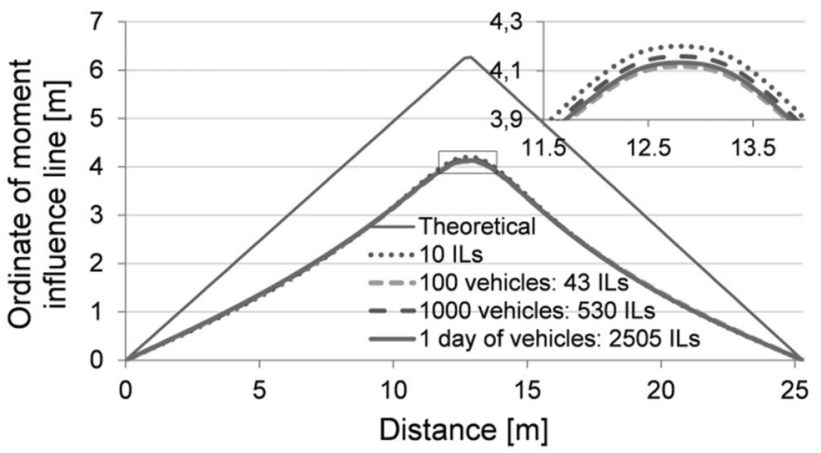

Fig. 10 The influence of the number of influence lines, with zoomed detail from the peak area (top right)

were calculated from all three-, four- and five-axle vehicles recorded in the samples of 15,100 and 1000 successive vehicles, and one full day of traffic. Within \pm 1 standard deviation interval, there were 7, 30, 445 and 1069 influence lines, respectively, which corresponded to $70-82.4 \%$ of all calculated influence lines.

The peak detail in the top right corner of Fig. 10 reveals that the IL averaged from merely ten individual ILs is only slightly different from the others obtained from significantly more individual ILs.

To quantify the convergence of ILs from all test bridges, the mean values of peak ordinates for the first $2,4,8,16,32$, etc. ILs were compared with the mean values of the complete sets of ILs. To minimise the effect of temperature, the data were first randomly shuffled. Figure 11 shows the relative differences of the mean peak values, for all bridges in Fig. 11a and individual beams of Bridge A in Fig. 11b. In the latter, the grey traces are from the period before bridge repair and the black traces from the period after it.

After 128 ILs the difference is well within $1 \%$ in all cases and within a few tenths of a percent after 1024 ILs. This quick convergence implies that the method is robust enough not only to evaluate the influence lines for B-WIM measurements but also to monitor their evolution as a part of the bridge monitoring process, as shown in Sect. 4 [5, 30, 42].

\section{Monitoring influence lines}

The shape of a bridge influence line changes as the key structural parameters change. The most apparent one is the temperature which affects the performance of all constrained structural elements. If the monitoring period is longer than 1 year, to consider the effect of temperature, we can assume that the remaining differences were due to changes in the bridge performance. In theory, it is possible to detect changes in superstructure stiffness and support performance, such as broken expansion joints or blocked 

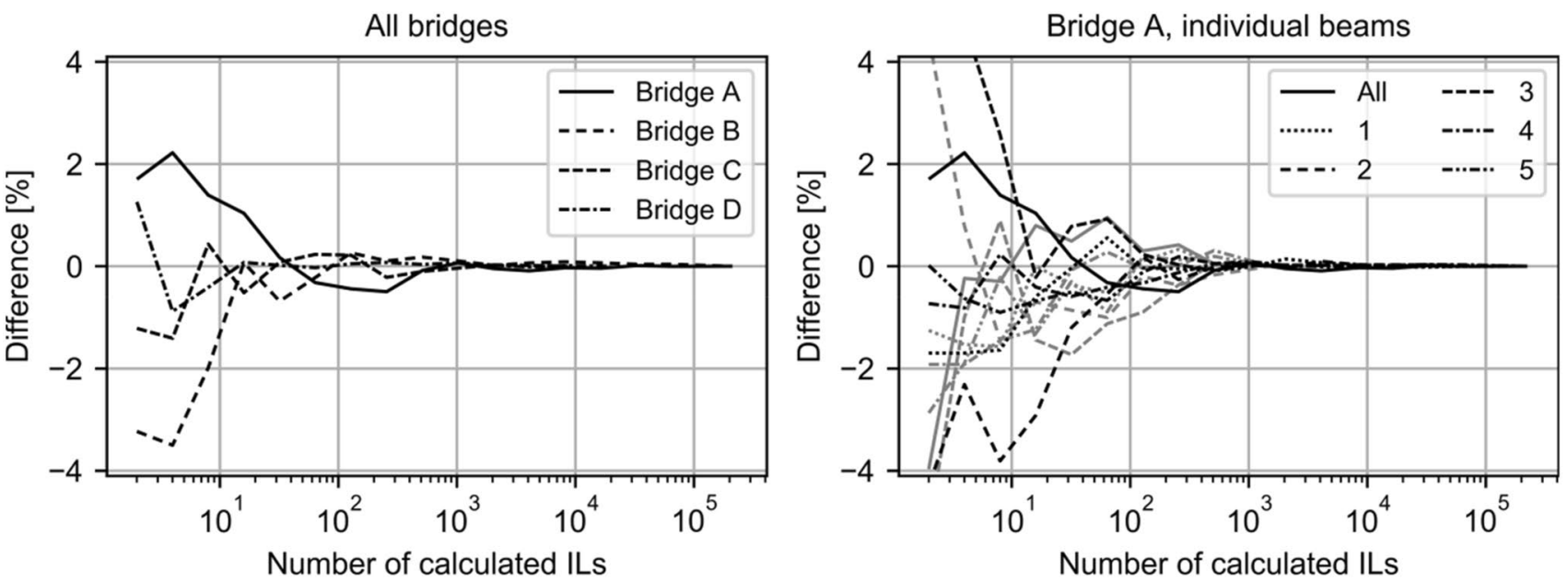

Fig. 11 The dependence of mean peak value on the number of calculated ILs

bearings. In reality, however, variations of stiffness, e.g. due to material deterioration, are slow and would probably have been discovered earlier during regular bridge inspections. Differences also have to be substantial to influence the monitored dynamic properties or the influence lines of the structural system. Consequently, the two main reasons to use the proposed method are the bridge parts that are hidden or are difficult to access and the fact that sufficiently thorough inspections of critical elements are only carried out at intervals of 5 or 6 years [44].

Another useful application of the proposed method is just to measure the influence lines, to evidence the real bridge performance under traffic loading. Having this information is vital for old bridges, designed as simply supported, but without bearings and expansion joints to allow such behaviour. From the point of traffic-induced load effects, these bridges perform much better than in theory, which we can only prove when considering the measured influence lines [44]. One such typical example is Test Bridge C.

\subsection{Parametrising influence lines}

Monitoring the boundary conditions required a tool that compared the statistically evaluated influenced lines measured by the B-WIM system with the analytical ones. Longterm monitoring of this parameter should give a good indicator of whether the conditions around the supports are changing and actions are needed.

The Euler-Bernoulli beam theory [45] defines three boundary conditions applicable to bridges-fixed, simply supported and rollers, where the latter two are, from the viewpoint of IL shape, identical. In the simply supported case, the ends are free to rotate, as there is no force to oppose rotation. With the fixed ends, they cannot rotate and the derivative at endpoints is zero. In real world, all measured
ILs fall somewhere between these two extremes [44]. For example, the bridge may have been designed as simply supported, but in reality, the system of bearings and expansion joints does not allow such behaviour, in particular, if they have deteriorated over time or are damaged. Other possible reasons are the continuous railings, safety barriers, deck and even asphalt layer.

In structural modelling, we use rotational springs to model behaviour between the two extremes. The stiffness of such a spring would be zero for simply supported bridges and infinite for completely fixed integral bridges. Instead of using spring stiffness directly, which does not say where we are between the two extreme cases, a coefficient of rotational stiffness, $F$, has been introduced. This coefficient defines the linear combination of the simply supported and fixed supported influence lines. Two coefficients, one at each end, $F_{\mathrm{L}}$ and $F_{\mathrm{R}}$, are needed to describe an arbitrary single-span influence line.

In Fig. 12, the values of coefficients for the simply supported influence line are defined as $F_{\mathrm{L}}=F_{\mathrm{R}}=0$ (or $0 \%$ ), while the values for the fixed-supported influence line are defined as $F_{\mathrm{L}}=F_{\mathrm{R}}=1$ (or $100 \%$ ). Realistic bridges with

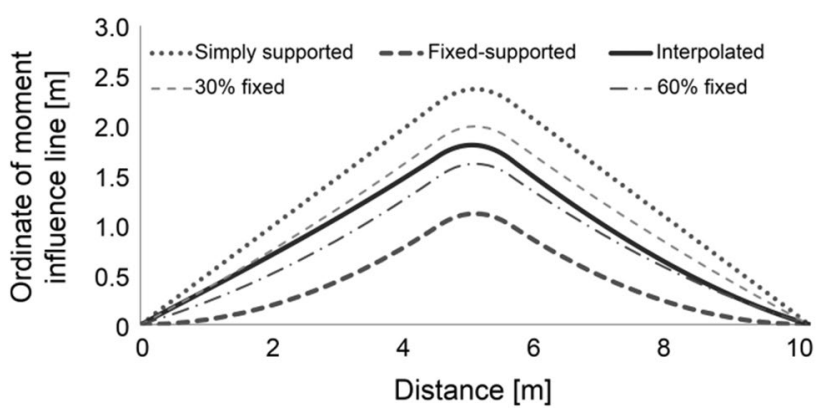

Fig. 12 Definition of rotation of the supports 
partially constrained supports have values of coefficients between 0 and $100 \%$. If the influence line is not symmetrical, a linear blend of two influence lines is used. For example, the interpolated influence line in Fig. 12 with coefficients $F_{\mathrm{L}}=30 \%$ and $F_{\mathrm{R}}=60 \%$ is calculated as

$I(x)=\frac{l-x}{l} I_{30}(x)+\frac{x}{l} I_{60}(x)$,

where $I_{30}(x)$ is the $30 \%$ fixed influence line, $I_{60}(x)$ is the $60 \%$ fixed influence line and $l$ is the length of the influence line, $10 \mathrm{~m}$ in this case. For multi-span bridges, a similar procedure is used, but only the rotational stiffness of the end supports is parametrised.

The measured influence lines from the initial setup of the B-WIM site are processed as shown in the example in Fig. 10, to obtain a mean initial influence line, and the degree of rotational stiffness is evaluated individually for both supports of each beam. When monitoring the influence lines, the evolution of the rotational stiffness coefficients is tracked and analysed for differences from the initial values.

\subsection{Sensitivity to temperature}

The influence lines calculated from the random traffic were averaged within equally sized temperature intervals that were defined based on the highest and the lowest measured temperature on each test bridge. As an example, the top graph in Fig. 13 displays the averaged influence line of Bridge $\mathrm{C}$ within five temperature ranges, calculated from over 8500 influence lines. The legend shows the average temperatures in these intervals. The bottom graph in the same figure gives the variation of coefficients of rotational stiffness with the temperature of left and right supports $F_{\mathrm{L}}$ and $F_{\mathrm{R}}$. All shapes and values of $F_{\mathrm{L}}$ and $F_{\mathrm{R}}$ represent the average results calculated from all influence lines within the specified temperature interval. Similarly, Fig. 14 shows the variation of $F_{\mathrm{L}}$ and $F_{\mathrm{R}}$ for all four test bridges, plotted on the same vertical scale. Table 1 summarises the results for all test bridges. For each temperature interval, the following results are given: mean and limit temperatures, number of influence lines considered and values of $F_{\mathrm{L}}$ and $F_{\mathrm{R}}$. Also, the integrals of the average influence lines in each temperature interval, $A_{\mathrm{IL}, T}$, where $T$ is the respected temperature range, were compared to the integral of the average influence line calculated from all records, $A_{\mathrm{IL}}$. The temperature sensitivity factor of the influence line, $\mathrm{TF}_{\mathrm{IL}, T}$, is then defined as

$\mathrm{TF}_{\mathrm{IL}, T}=\frac{A_{\mathrm{IL}, T}}{A_{\mathrm{IL}}}$,

and gives a reliable indication of the variation of bending moments due to temperature.
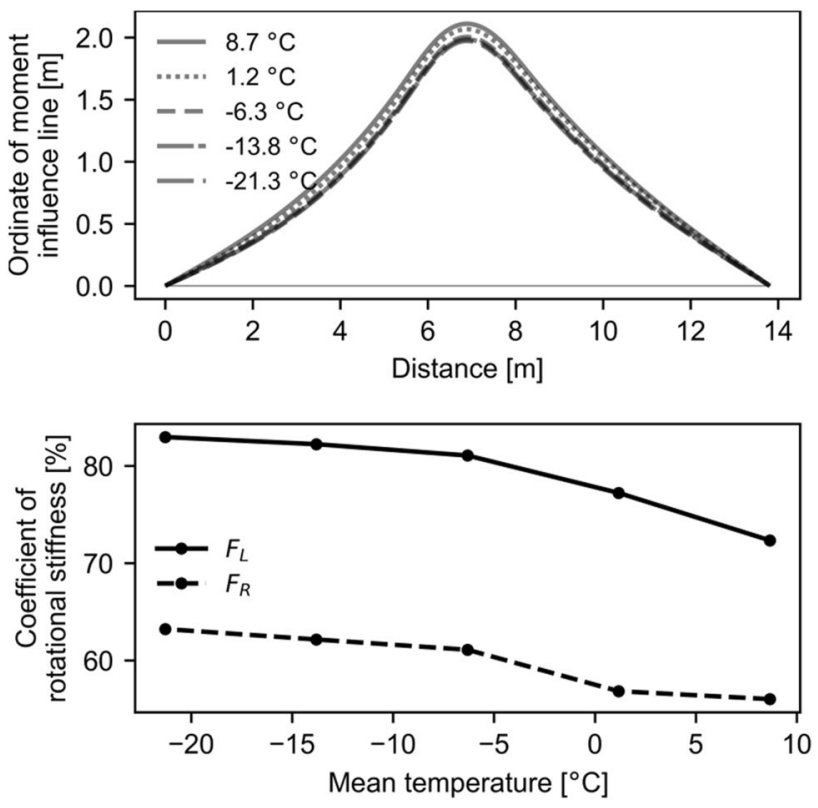

Fig. 13 Bridge $\mathrm{C}$-averaged influence lines (top), and variations of $F_{\mathrm{L}}$ and $F_{\mathrm{R}}$ within five temperature intervals (bottom)

Influence lines of all bridges were affected by temperature. The reasons for variations are related to soil pressure, asphalt characteristics and construction details, which change with temperature. As expected, the stiffness of all structures decreases with temperature. The change is more apparent in the results of Bridges $\mathrm{C}$ and $\mathrm{D}$, where a considerable part of measurements was taken at sub-zero temperatures. The $\mathrm{TF}_{\mathrm{IL}, T}$ values from Table 1 reveal that the bending moments on these two bridges during the hottest months increase for 7 and $11 \%$ if compared to the coldest winter period. Bridge B behaved in a similar way [33], but, due to the low number of records at sub-zero temperatures, this cannot be seen in Fig. 14. The behaviour of the Bridge A should be taken with some reserve as the traffic regime changed during the two sets of measurements.

The influence of temperature on bridge behaviour is considerably more complex than can be realistically accounted for, even with very sophisticated finite-element analytical models that take into account heat transfer and exposure to the sun [31]. Detailed studies of more measurements at different sites might give better insight into this phenomenon.

\subsection{Monitoring of changes of influence lines}

No sufficiently long-lasting measurements exist at the moment which would allow monitoring changes in the behaviour of bridge supports. Therefore, we have tested the efficiency of the proposed procedure on the Bridge A, on which the rubber expansion joints were, during comprehensive rehabilitation works, replaced with the asphalt 

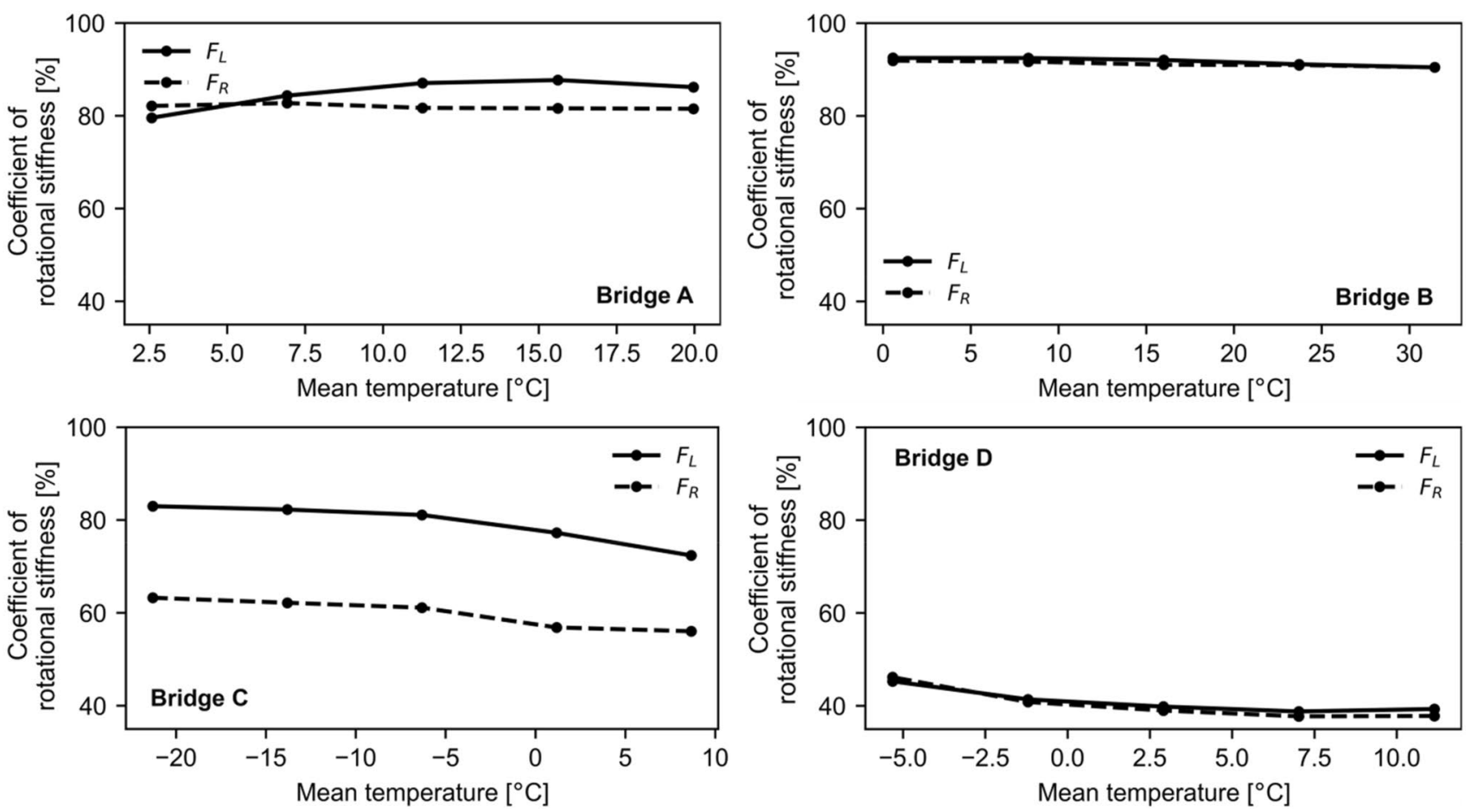

Fig. 14 Variations of $F_{\mathrm{L}}$ and $F_{\mathrm{R}}$ with temperature for all test bridges

Table 1 Results of influence line analyses of all test bridges

\begin{tabular}{lrrrrrrl}
\hline & $T_{\text {mean }}$ & \multicolumn{1}{c}{$T_{\text {from }}$} & \multicolumn{1}{c}{$T_{\text {to }}$} & \multicolumn{1}{c}{$N$} & $\mathrm{TF}_{\mathrm{IL}, T}$ & $F_{\mathrm{L}}(\%)$ & $F_{\mathrm{R}}(\%)$ \\
\hline Bridge A & 20.0 & 17.8 & 22.1 & 2285 & 0.994 & 86.2 & 81.5 \\
& 15.6 & 13.4 & 17.8 & 5786 & 0.982 & 87.7 & 81.6 \\
& 11.3 & 9.1 & 13.4 & 7315 & 0.986 & 87.0 & 81.7 \\
Bridge B & 6.9 & 4.7 & 9.1 & 2701 & 0.999 & 84.3 & 82.7 \\
& 2.6 & 0.4 & 4.7 & 1787 & 1.039 & 79.6 & 82.1 \\
& 31.4 & 27.6 & 35.3 & 2265 & 1.017 & 90.5 & 90.5 \\
& 23.7 & 19.9 & 27.6 & 12,247 & 1.007 & 91.1 & 91.0 \\
Bridge C & 16.0 & 12.1 & 19.9 & 52,577 & 0.999 & 92.0 & 91.0 \\
& 8.3 & 4.4 & 12.1 & 83,697 & 0.990 & 92.5 & 91.7 \\
& 0.6 & -3.3 & 4.4 & 45,775 & 0.988 & 92.5 & 91.9 \\
& 8.7 & 4.9 & 12.4 & 1636 & 1.066 & 72.4 & 56.0 \\
& 1.2 & -2.6 & 4.9 & 1841 & 1.031 & 77.2 & 56.8 \\
Bridge D & -6.3 & -10.1 & -2.6 & 2571 & 0.981 & 81.1 & 61.1 \\
& -13.8 & -17.5 & -10.1 & 1902 & 0.967 & 82.2 & 62.2 \\
& -21.3 & -25.0 & -17.5 & 711 & 0.955 & 83.0 & 63.2 \\
& 11.1 & 9.1 & 13.2 & 2498 & 1.020 & 39.0 & 37.6 \\
& 7.0 & 5.0 & 9.1 & 6867 & 1.021 & 38.6 & 37.8 \\
& 2.9 & 0.9 & 5.0 & 10,009 & 1.011 & 39.8 & 38.9 \\
& -1.2 & -3.2 & 0.9 & 5746 & 0.997 & 41.2 & 40.6 \\
& -5.3 & -7.3 & -3.2 & 1375 & 0.951 & 45.5 & 46.4 \\
\hline
\end{tabular}

ones. The effect of this measure on the shape of influence lines was evaluated by averaging influence lines calculated from bridge responses caused by two-axle trucks and fiveaxle semi-trailers. 2102 influence lines were derived from measurements before rehabilitation and 211,744 influence lines after it. The traffic regimes during both measurements were substantially different (Fig. 15), but in both cases, only the traffic from the driving lane was used. Figure 16 displays 

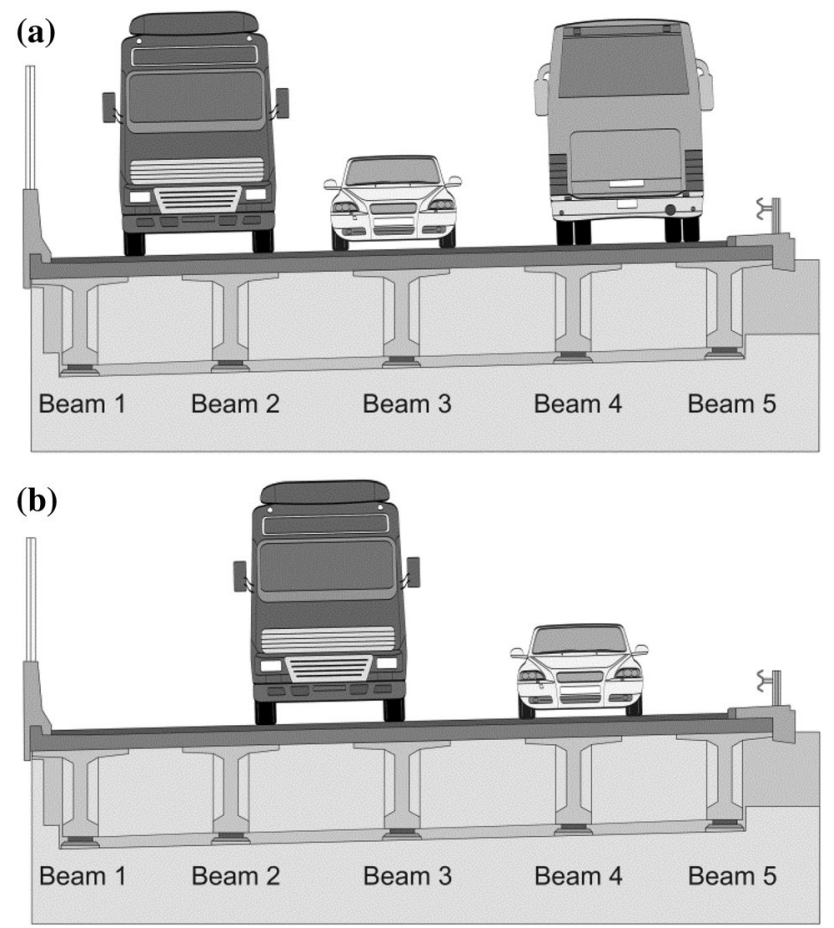

Fig. 15 Bridge $\mathrm{A}$-traffic regimes during measurements before (a) and after bridge rehabilitation (b)

in the top-left diagram the influence lines calculated from the sum of strain responses of all five beams. The remaining diagrams present the results derived only from the measured strains from individual beams, from the Beam 1 under the shoulder to Beam 5 facing the adjacent structure. From the diagrams, it can be concluded that the results for Beams 2 and 4 have practically not changed, those for Beams 1 and 5 indicate less stiff and for the Beam 3 much stiffer behaviour. Table 2 summarises the values and changes in the coefficients of rotational stiffness in $\%$.

The results yield the following conclusions:

- although in theory the bridge is simply supported by design and should have coefficients of rotational stiffness close to zero, all measured values before the replacement of bearings and expansion joints exceed $20 \%$ and after the replacement $18 \%$;

- support constraints of Beams 2 and 4 have in absolute terms not changed for more than 5\% (on average for less than $1 \%$ ); the relative changes of rotational stiffness before and after replacement of expansion joints increase for up to $3.6 \%$, with the average relative difference of $2 \%$;

- changes of rotational stiffness of Beams 1 and 5 are more substantial, reaching 6 and 9\%, respectively, which corresponds to up to $30 \%$ relative change; however, these are the two edge beams which carry a smaller portion of traffic loading;
- after rehabilitation, the support constraints of Beam 3 increased for a significant 29 and 35\%.

The influence lines of Beam 3, after the rehabilitation, and of Beam 2, before and after rehabilitation, are considerably more constrained (less simply supported) than the other three. The reason for the significant change of Beam $3 \mathrm{IL}$ is the traffic regime that has altered between the measurements (Fig. 15). Before rehabilitation, the heavy vehicles in the driving lane were crossing the bridge predominantly over the Beam 2 and far from Beam 3. During the second set of measurements, they were almost equally loading these two beams. It is known from the structural theory that influence lines on bridges with explicit plane behaviour, such as slabs or grillages, only vaguely describe their behaviour under traffic loading and that influence surface would give more accurate results. However, according to [2], measuring an influence surface is challenging as it would require a vast number of vehicle runs at different lateral positions. An approximation of a measured influence surface was calculated for the Bridge B, which was instrumented with 12 strain sensors located at its mid-span equidistantly across the width of the slab. Figure 17 displays a 3-D plot of connected influence lines calculated from the strains of individual sensors, caused by traffic in the driving lane, with wheels close to sensors S5 and S7 [33], in a similar way as presented in Fig. 15 for Beams 1 to 5. Due to the horizontal plane effects, the shapes of the influence lines away from the wheel track change from more integral to more simply supported-like. In other words, the impact of rotational stiffness of supports in lateral direction decreases with distance from the source of loading. The same trend is observed on Bridge A. There the influence lines under the wheel are considerably sharper, due to the higher rotational stiffness, than those of the beams not directly exposed to loading (Fig. 16 and Table 2). These experimental results are in good agreement with the analytical calculation of the shape of the influence surface for a slab bridge [46].

\section{Conclusions}

Possibilities of using bridge weigh-in-motion systems to monitor bridge influence lines were investigated. It has been shown that the proposed method to calculate influence lines from strain records measured by a bridge weigh-in-motion system provides robust results. This not only allows using these influence lines as one of the critical parameters of bridge weigh-in-motion measurements but also to monitor them to detect potential changes in bridge performance.

Results from four case study bridges demonstrate that temperature affects the shape of the influence lines of most bridges, even those designed as simply supported. These 

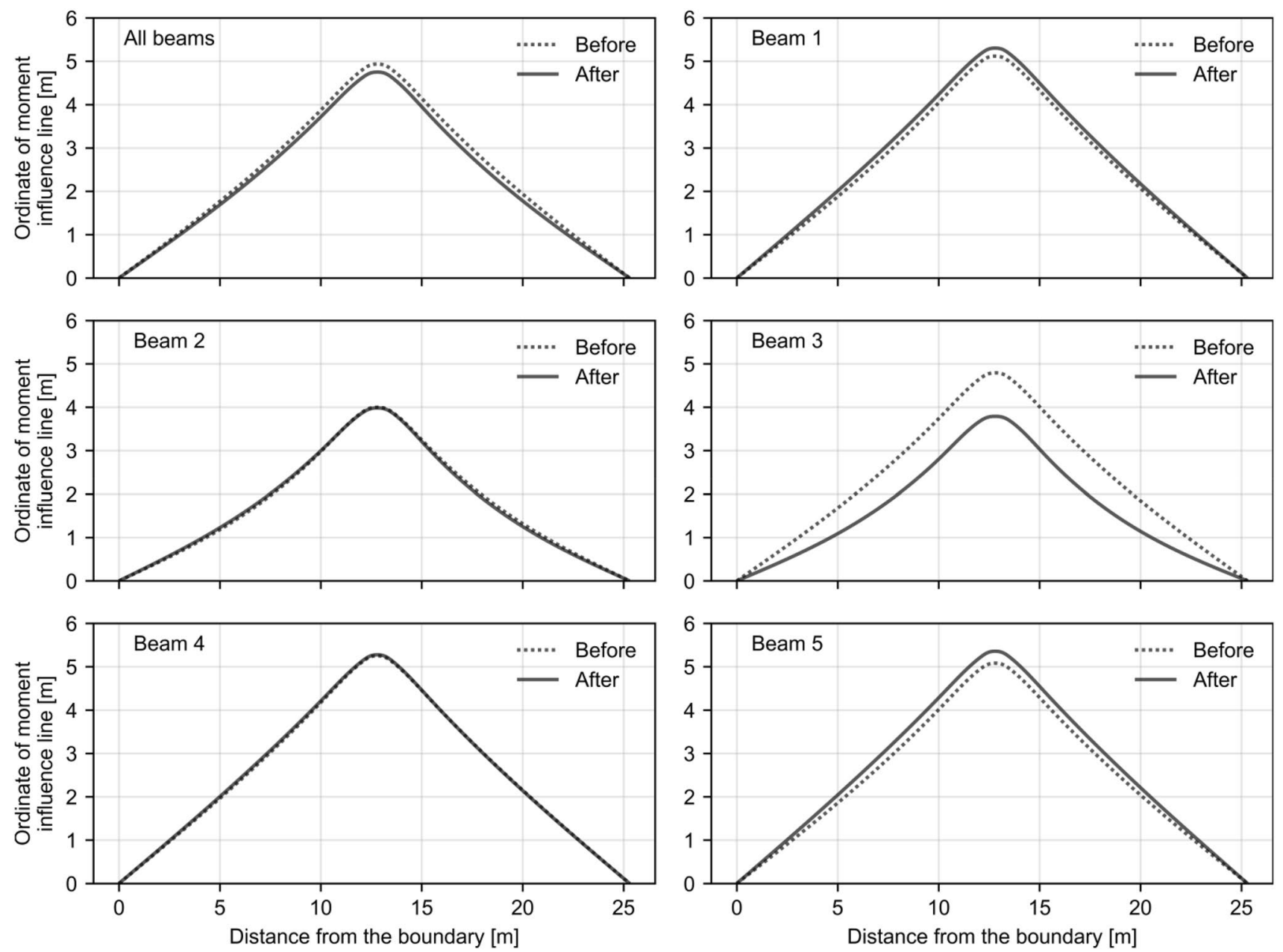

Fig. 16 Bridge A-influence lines before and after replacement of the expansion joints

Table 2 Coefficients of rotational stiffness in percent before and after replacement of the expansion joints

\begin{tabular}{|c|c|c|c|c|c|c|c|c|c|c|c|c|}
\hline & \multicolumn{3}{|c|}{ Before joint replacement } & \multicolumn{3}{|c|}{ After joint replacement } & \multicolumn{3}{|c|}{ Difference after-before of } & \multicolumn{3}{|c|}{ Relative difference in } \\
\hline & $F_{\mathrm{L}}(\%)$ & $F_{\mathrm{R}}(\%)$ & $F(\%)$ & $F_{\mathrm{L}}(\%)$ & $F_{\mathrm{R}}(\%)$ & $F(\%)$ & $F_{\mathrm{L}}(\%)$ & $F_{\mathrm{R}}(\%)$ & $F(\%)$ & $F_{\mathrm{L}}(\%)$ & $F_{\mathrm{R}}(\%)$ & $F(\%)$ \\
\hline All beams & 37 & 31 & 34 & 40 & 39 & 40 & 3 & 9 & 6 & 7 & 29 & 17 \\
\hline Beam 1 & 32 & 24 & 28 & 25 & 20 & 22 & -7 & -5 & -6 & -23 & -19 & -21 \\
\hline Beam 2 & 67 & 60 & 64 & 63 & 66 & 64 & -4 & 5 & 0 & -6 & 8 & 1 \\
\hline Beam 3 & 42 & 35 & 39 & 71 & 70 & 70 & 29 & 35 & 32 & 68 & 101 & 83 \\
\hline Beam 4 & 28 & 20 & 24 & 25 & 21 & 23 & -3 & 1 & -1 & -10 & 7 & -3 \\
\hline Beam 5 & 33 & 26 & 29 & 23 & 18 & 21 & -10 & -8 & -9 & -29 & -31 & -30 \\
\hline
\end{tabular}

effects are more pronounced on integral structures and, in particular, at sub-zero temperatures when freezing of some parts of the structure and the surrounding soil changes the boundary conditions. On the test bridge $\mathrm{C}$ the bending moments, due to the higher rotational stiffness of the supports during the freezing period, decreased for more than $11 \%$ compared to the results obtained during the summer months.
Long-term verification of the proposed procedure was not viable, as damages that cause a detectable change of stiffness of the structure develop over many years. Consequently, the IL monitoring was verified through measurements on a bridge which rubber expansion joints were replaced with the asphalt ones. The results of the analysis confirmed that the applied modifications affected the rotational stiffness of the supports, detected from the changing shapes of the 


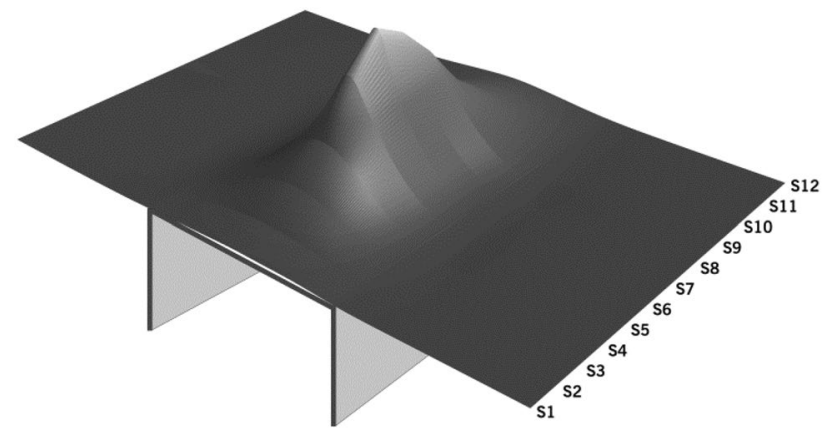

Fig. 17 Bridge B-changing shapes of measured influence lines due to traffic in the driving lane

influence lines. A further comprehension of the study was that using the sum of strain signals from all measurement points, as applied to calculate influence lines for bridge weigh-in-motion measurements, is not sufficient for their long-term monitoring. For this purpose, the influence lines at each measurement point are required.

What remains to be investigated is the relation between the detected IL differences and the actual damages, as experienced engineers might find many of them much sooner during regular bridge inspections. The opportunity of the proposed method is to discover hidden defects and brittle failures of structural components, which affect the shape of the influence lines, well before the next scheduled bridge inspection takes place. Also, if accomplished as a side result of B-WIM weighing, the proposed procedure would cost just a fraction of a standalone monitoring system installation.

Acknowledgements The authors would like to express their gratitude for the support received from the European Commission's 7th Framework Programme projects BridgeMon (2012-14) and TRIMM (2011-14) and the Slovenian Research Agency programme P2-0273 Building Structures and Materials.

Open Access This article is licensed under a Creative Commons Attribution 4.0 International License, which permits use, sharing, adaptation, distribution and reproduction in any medium or format, as long as you give appropriate credit to the original author(s) and the source, provide a link to the Creative Commons licence, and indicate if changes were made. The images or other third party material in this article are included in the article's Creative Commons licence, unless indicated otherwise in a credit line to the material. If material is not included in the article's Creative Commons licence and your intended use is not permitted by statutory regulation or exceeds the permitted use, you will need to obtain permission directly from the copyright holder. To view a copy of this licence, visit http://creativecommons.org/licenses/by/4.0/.

\section{References}

1. Wenzel H (2008) Health monitoring of bridges. Wiley, Hoboken
2. Jacob B, OBrien E, Jehaes S (2002) Weigh-in-motion of road vehicles: final report of the COST 323 action, Brussels

3. Žnidarič A, Kalin J, Kreslin M (2017) Improved accuracy and robustness of bridge weigh-in-motion systems. Struct Infrastruct Eng. https://doi.org/10.1080/15732479.2017.1406958

4. ARCHES D10 (2009) Recommendations on dynamic amplification allowance. European Commission, Brussels, https://www. fehrl.org/library?id=5918. Accessed 28 July 2020

5. Žnidarič A, Lavrič I (201) Applications of B-WIM technology to bridge assessment. In: Proceedings of the fifth international conference on bridge maintenance, safety and management IABMAS2010, Philadelphia, USA

6. Goble G, Moses F, Pavia A (1976) Application of a bridge measurement system. In: Transportation Research Record No. 579, Washington DC, pp 36-47

7. Moses F (1979) Weigh-in-motion system using instrumented bridges. ASCE Transport Eng J 105:233-249

8. Peters RJ (1984) AXWAY - a system to obtain vehicle axle weights. In: Proceedings of the 12th ARRB Conference, Melbourne

9. Peters RJ (1986) CULWAY - an unmanned and undetectable highway speed weighing system. In: Proceedings of the 13th ARRB Conference, Melbourne

10. Snyder RE (1992) Field trials of low-cost bridge WIM. Publication FHWA-SA-92-014, Washington, DC

11. OBrien EJ, Žnidarič A (2001) Report of WAVE project work package 1.2—Bridge WIM, Dublin, Ljubljana: UCD \& ZAG

12. Dempsey AT, Jacob B, Carracilli J (1998) The use of instrumented orthotropic bridges for determining vehicle weights, dimensions and parameter. In: Proceedings of the 5th international symposium on heavy vehicles weights and dimensions, Brisbane, Australia

13. Quilligan M, Karoumi R, OBrien EJ (2002) Development and testing of a 2-dimensional multi-vehicle bridge-WIM algorithm, third international conference on weigh-in-motion (ICWIM3), Orlando

14. Gonzales A, OBrien EJ (1998) The development of a dynamic bridge weigh-in-motion algorithm. In: Proceedings of 2nd European conference on weigh-in-motion, Lisbon

15. Znnidarič A, Lavrič I, Kalin J (2010) Latest practical developments in the Bridge WIM technology. In: Proceedings of the fifth international conference on bridge maintenance, safety and management IABMAS2010, Philadelphia, USA

16. ERTRAC (2016) From collaborative research projects to market deployment: 12 success stories. ERTRAC, Brussels

17. OBrien EJ, Žnidarič A, Ojio T (2008) Bridge weigh-in-motionlatest developments and applications world wide. In: Jacob B, Obrien EJ, OConnor A, Bouteldja M (eds) Proceedings of the 5th international conference on weigh-in-motion (ICWIM5), Paris

18. Ojio T, Yamada K, Kainuma S, Obata T (1998) Furuichi T (1998) Estimation of traffic loads using strain recording in orthotropic steel deck. J Struct Eng (JSCE) 44A:1141-1151 (in Japanese)

19. Ojio T, Carey C, OBrien EJ, Doherty C, Taylor SE (2016) Contactless bridge weigh-in-motion. J Bridge Eng 21(7):04016032

20. Helmi K, Taylor T, Ansari F (2015) Shear force-based method and application for real-time monitoring of moving vehicle weights on bridges. J Intell Mater Syst Struct 26(5):505-516

21. Bao T, Babanajad SK, Taylor T, Ansari F (2016) Generalized method and monitoring technique for shear-strain-based bridge weigh-in-motion. J Bridge Eng 21(1):04015029

22. Law S, Chan T, Zeng A (1999) Moving force identification: a frequency and time domain analysis. ASME J Dyn Syst Meas Control 12:394-401

23. Rowley W (2007) Moving force identification of axle forces on bridges, PhD Thesis: University College Dublin

24. Deesomsuk T, Pinkaew T (2009) Effectiveness of vehicle weight estimation from bridge weigh-in-motion. Adv Civ Eng 2009:14 
25. Corbally R, Kreslin M, Žnidarič A, Cantero D, Kalin J (2013) Technical specification for the class A bridge-WIM system, BridgeMon D1.2 report. ROD, Dublin

26. Richardson J, Jones SL, Brown A, OBrien EJ, Hajializadeh D (2014) On the use of bridge weigh-in-motion for overweight truck enforcement. Int J Heavy Veh Syst 21(2):83-104

27. Zhao H, Uddin N, OBrien EJ, Xudong S, Zhu P (2014) Identification of vehicular axle weights with a bridge weigh-in-motion system considering transverse distribution of wheel loads. J Bridge Eng 19(3):04013008

28. Christenson R, Motaref S (2016) Dual purpose bridge health monitoring and weigh-in-motion (BWIM). Department of Civil and Environmental Engineering, School of Engineering, University of Connecticut, Storrs

29. Yu Y, Cai C, Deng L (2016) State-of-the-art review on bridge weigh-in-motion technology. Adv Struct Eng 1-17:1514-1530

30. Ralbovsky M, McRobbie S, Šajna A, Leban MB, Sekulič D, Žnidarič A, Kreslin M, Legat A, Dallinger S, Dieng L, Jurič S, Kwapisz M, Santos JP, Silveira P (2014) Final report of advanced bridge monitoring techniques-TRIMM report D3.2. AIT, Vienna

31. Cantero D, Kreslin M, Corbally R (2013) Numerical models of three bridge types, BridgeMon D1.1 Report. Rodis, Dublin

32. Corbally R, Žnidarič A, Leahy C, Kalin J, Hajializadeh D, Zupan E, Cantero D (2014) Algorithms for improved accuracy of static bridge-WIM system, BridgeMon D1.3 report. ROD, Dublin

33. Žnidarič A (2017) Influence of number and quality of weigh-inmotion data on evaluation of load effects on bridges, Doctoral dissertation. University of Ljubljana, Ljubljana

34. Kirkegaard P, Neilsen S, Enevoldsen I (1997) Heavy vehicles on minor highway bridges - calculation of dynamic impact factors from selected crossing scenarios, ISSN 1395-7953, R9722nd edn. Department of Building Technology and Structural Engineering, Aalborg University, Aalborg

35. Caprani CC (2013) Lifetime highway bridge traffic load effect from a combination of traffic states allowing for dynamic amplification. J Bridge Eng 18(9):901-909
36. Kalin J, Žnidarič A, Kreslin M (2015) Using weigh-in-motion data to determine bridge dynamic amplification factor. In: EVACES' 15, 6th International Conference on Experimental Vibration Analysis for Civil Engineering Structures, Dübendorf

37. Press WH, Teukolsky SA, Vetterling WT, Flannery BP (2007) Numerical recipes: the art of scientific computing, 3rd edn. Cambridge University Press, Cambridge

38. Hirachan J, Chajes M (2005) Experimental influence lines for bridge evaluation. Bridge Struct Assess Des Constr 4:405-412

39. Wang N-B, He L-X, Ren W-X, Huang T-L (2017) Extraction of influence line through a fitting method from a bridge dynamic response induced by a passing vehicle. Eng Struct 151:648-664

40. OBrien J, Quilligan MJ, Karoumi R (2006) Calculating an influence line from direct measurements. In: Proceedings of the institution of civil engineers-bridge engineering 159(1), pp. 31-34

41. Cebon D (1999) Handbook of vehicle-road interaction. Taylor \& Francis, London

42. ARCHES D16 (2009) Recommendations on the use of soft, diagnostic and proof load testing, Brussels: European Commission, https://www.fehrl.org/library?id=5924. Accessed 28 July 2020

43. Žnidarič A, Kreslin M (2012) Structures performance assessment, HeROAD report 2.1. ERANET Road II, Ljubljana. http://www. eranetroad.org

44. Žnidarič A, Herga L, Pirman B, Willenpart T, Hevka P, Močnik C, Ružič D (2015) Management of bridges in Slovenia, National Report. PIARC-World Road Congress, Seoul

45. Timoshenko S (1953) History of strength of materials. McGrawHill, New York

46. Kawai T (1957) Influence surfaces for bridge slabs. Lehigh Civil and Environmental Engineering, Bethlehem

Publisher's Note Springer Nature remains neutral with regard to jurisdictional claims in published maps and institutional affiliations. 